\title{
Jezik SMS-jev in SMS-komunikacija
}

\author{
Mija Michelizza
}

IZVLEČEK: V prispevku predstavljamo SMS (angl. Short Message Service) kot vsesplošno razširjeno komunikacijsko sredstvo. Kaj danes pomeni pismenost, smo se prepričali na primeru SMS-komunikacije, ki predstavlja pomemben del našega vsakdana. SMS-ji nadomeščajo tako govorjena kot tudi pisana besedila in so lahko del neuradne ali uradne SMS-komunikacije. Svetovni splet, sleng, vsestransko prodirajoča angleščina ter omejitev na 160 znakov so odločilno vplivali na nastanek novega koda - jezika SMS-jev. Predstavljeno je tudi, kolikšen vpliv imajo na pisanje SMS-jev najrazličnejši poskusi standardizacije jezika SMS-jev.

ABSTRACT: This article discusses SMS (Short Message Service) as a universally widespread means of communication. The notion of literacy is assessed on SMS communication, which represents an important part of everyday life. Short text messages are replacing both spoken and written texts and may be part of casual or formal SMS communication. The World Wide Web, slang, the general penetration of English, and a limitation to 160 characters have had a decisive influence on the emergence of a new code: SMS language. The effect of various attempts to standardize SMS language is also examined.

\section{Uvod}

Prispevek $^{1}$ predstavlja SMS ${ }^{2}$ kot komunikacijsko sredstvo, ki je danes vsesplošno razširjeno. Zanimalo pa nas je, kakšna je njegova preteklost ter kolikšne so možnosti, da njegovo vlogo v kratkem prevzamejo MMS-ji, ${ }^{3}$ saj se zdi, da ti niso

1 Članek temelji na spoznanjih in raziskavi iz avtoričinega diplomskega dela Pragmatična primerjava jezika SMS-jev v slovenščini in španščini, Ljubljana, Filozofska fakulteta, 2006, mentorici izr. prof. dr. Simona Kranjc in izr. prof. dr. Jasmina Markič. Nekatera tamkajšnja spoznanja nadgrajuje.

2 Angl. Short Message Service.

3 Angl. Multimedia Messaging System. 
tako popularni kot SMS-ji. Da pismenost ne pomeni več zgolj sposobnosti branja in pisanja (Strehovec 2004, 83), smo se prepričali na primeru SMS-komunikacije, ki danes predstavlja pomemben del našega vsakdana: lahko nadomešča telefonski klic, s SMS-jem pošljemo voščilo, povabimo na zabavo, dobimo želeno informacijo, glasujemo, darujemo ... Nadomešča torej govorjena in pisana besedila in je lahko del neuradne ali uradne SMS-komunikacije. Svetovni splet, sleng, vsestransko prodirajoča angleščina ter omejitev na 160 znakov so odločilno vplivali na nastanek novega koda - jezika SMS-jev. Gre za način pisanja, ki se je pojavil predvsem v okviru neuradne SMS-komunikacije, nekatere značilnosti pa so opazne tudi v uradni. Zanimalo nas je tudi, kolikšno vlogo imajo na pisanje SMS-jev najrazličnejši poskusi standardizacije jezika SMS-jev ter v kakšni meri se ta kaže v praksi.

\section{Mobilna telefonija in SMS}

Razvoj mobilnih telekomunikacij se je začel v Skandinaviji s t. i. prvo generacijo $\mathrm{NMT},{ }^{4} \mathrm{ki}$ je bila analogna. V Sloveniji je bila uvedena julija 1991 in dokončno ukinjena 31. decembra 2005. Digitalni sistem mobilnih komunikacij je bil uveden z drugo generacijo - GSM, ${ }^{5}$ katere glavna naloga je prenos govornega signala, kot dodatna možnost pa se pojavi prenos podatkov. S to generacijo so bili torej uvedeni tudi SMSji. ${ }^{6}$ Zelo hitro so se razširili med mlajšimi uporabniki mobilnih telefonov in čeprav je že nadgradnja z vmesno generacijo GPRS 7 ponudila konkurenčne MMS-je, se zdi, da jih ti vsaj zaenkrat še ne bodo dohiteli. Izpopolnitev v prenosu podatkov, predvsem v hitrosti in kakovosti, predstavlja tretja generacija mobilne telefonije UMTS. ${ }^{8}$

Mobilni telefon je najpogostejši stik, torej fizični kanal za prenos SMS-jev. Pravzaprav sta $v$ komunikacijo vključena dva mobilna telefona, prvi pošiljateljev in drugi naslovnikov, eden ali drugi pa sta lahko nadomeščena z računalnikom. SMS-ji so lahko poslani z računalnika, zlasti ko je naslovnikov več, saj tak način omogoča hitrejšo storitev. Z računalnika, z nekaterih spletnih strani, je mogoče brezplačno pošiljati SMS-je na mobilne telefone uporabnikov različnih operaterjev. Prejeti SMS-ji, poslani z mobilnega telefona, se največkrat zbirajo na računalniku v situacijah, ko obstaja možnost, da je naenkrat poslano veliko število SMS-jev. Tovrstne storitve se uporabljajo na radiu, televiziji itd. Prav tako je mogoče z modernejšega mobilnega telefona poslati SMS v predal elektronske pošte, torej bo naslovnik do sporočila prišel prek računalnika.

Kaj je torej SMS? SMS je dodatna storitev v omrežju GSM/UMTS, ki omogoča sprejemanje, pošiljanje in shranjevanje kratkih tekstovnih sporočil. SMS-ji so teksti

4 Angl. Nordic Mobile Telephone.

5 Angl. Global System for Mobile Telecommunications.

${ }^{6}$ Izumitelj SMS-ja naj bi bil finski uslužbenec državne družbe za pošto in telekomunikacije Posti Matti Makkonen. Idejo je predstavil na konferenci o prihodnosti mobilnih telekomunikacij v Kopenhagnu jeseni 1982. Šele čez deset let, 3. decembra 1992, pa je bil poslan prvi SMS. Inženir Neil Papworth ga je z računalnika poslal na mobilni telefon Richarda Jarvisa, takrat direktorja na Vodafone UK. Sporočilo se je glasilo »Marry Christmas«.

7 Angl. General Packet Radio Service.

\footnotetext{
8 Angl. Universal Mobile Telecommunications System.
} 
z do največ 160 različnih črk, številk in znakov, ${ }^{9}$ ki se pošiljajo prek SMS-centra za prenašanje sporočil v omrežju GSM/UMTS. ${ }^{10}$

V začetku SMS-jem niti proizvajalci mobilnih telefonov niti operaterji niso dajali prednosti, prav tako še niso vedeli, kako to novost tržno izkoristiti. Po nekaterih podatkih so storitev SMS-jev primarno razvili za podajanje informacij borznega dogajanja in horoskopov. Danes so SMS-ji splošno razširjeni, ne le med mladimi, tekmeca pa imajo v MMS-jih, ki sicer postajajo cenovno vse dostopnejši, vendar v rabi zaostajajo za SMS-ji. Leta 2002, ko se je v Evropi prvič pojavila možnost pošiljanja MMS-jev, je storitev izgledala enostavna za uporabo, vendar tehnologije še niso bile dovolj razvite. Še vedno ostaja nekaj pomanjkljivosti, čeprav so tehnologije iz dneva v dan boljše. Na raznih športnih ali glasbenih prireditvah sicer pogosto vidimo obiskovalce, ki z mobilnim telefonom $\mathrm{v}$ roki fotografirajo dogodek, vendar raziskave (Informa Telecoms \& Media) kažejo, da je število poslanih MMS-jev še vedno znatno nižje od števila poslanih SMS-jev. Ker za Slovenijo podatki niso znani, vzamimo za primer Italijo, ${ }^{11}$ kjer je bilo v prvem četrtletju 2006 število poslanih SMS-jev na uporabnika 100, povprečen uporabnik istega operaterja pa je v istem obdobju poslal le malo več kot 1 MMS. Podobni rezultati so tudi v drugih državah.

\section{Gradivo}

Avtorica članka je v svoji diplomski nalogi v sklopu empiričnega dela analizirala dve skupini SMS-jev. »Neuradni« in »uradni« SMS-ji sta zbirki SMS-jev, ${ }^{12}$ ki sta nastali v sklopu avtoričine diplomske naloge. Prva obsega SMS-je, ki so jih dobesedno iz svojih mobilnih telefonov prepisali anketiranci, $v$ anketi pa je bilo tudi besedilo, ki so ga dijaki morali zapisati na način, kot bi ga zapisali v SMS-ju. Vsi citirani SMS-ji, ki sodijo v skupino »neuradnih« SMS-jev, so bili zbrani v anketi. Anketa je bila izvedena 24. oktobra 2005 na Gimnaziji Poljane v Ljubljani. Anketiran je bil 2. letnik, prisotnih je bilo 30 dijakov, njihova starost je bila 15 in 16 let. Primer ankete in zbrani SMS-ji so dostopni v prilogah avtoričinega diplomskega dela. Druga zbirka, »uradni« SMS-ji, pa vključuje razna obvestila, oglase, informacije ipd., ki jih je avtorica sama zbrala. Primeri v pričujoči razpravi so dobesedni prepisi teh SMS-jev. ${ }^{13}$

\section{Uradna in neuradna SMS-komunikacija}

SMS-komunikacijo si največkrat predstavljamo kot rabo SMS-ja, ki ga poši-

9 Standardna velikost SMS-ja je 140 bajtov. V latinični pisavi je en znak velik 7 bitov (1 bajt $=8$ bitov), kar pomeni, da v en SMS lahko napišemo do vključno 160 znakov. SMS $\mathrm{v}$ cirilici in nekaterih drugih pisavah je dolg le do 70 znakov, saj je velikost enega znaka kar 2 bajta.

${ }^{10}$ Definicija je povzeta po Slovarčku pojmov iz Mobitelove publikacije Dobrodošli!

${ }^{11}$ Operater TIM.

${ }^{12}$ Zbirka »neuradnih« SMS-jev obsega 76 primerov, »uradnih« SMS-jev je 21. Gradivo obeh zbirk diplomske naloge je količinsko primerljivo z zbirkama španskih SMS-jev.

${ }^{13}$ Potrebno je poudariti, da sta zbirki ločeni na podlagi načina pridobitve in da bi nekateri od »neuradnih« SMS-jev bolj sodili v sklop uradne SMS-komunikacije, saj ob izvajanju ankete ni bilo izrecno naročeno, naj dijaki prepišejo SMS-je neuradne komunikacije. 
ljatelj s svojega mobilnega telefona pošlje na mobilni telefon naslovnika, SMS pa napisan na način, ki se je razširil predvsem med mladimi, torej da $\mathrm{v}$ besedilu lahko opazimo leksikološke, skladenjske, oblikoslovne in fonetične spremembe jezika. Gre za primer neuradne SMS-komunikacije, v okviru katere jezik SMS-jev opredelimo v ožjem smislu besede. V širšem smislu jezik SMS-jev razumemo kot vsakršno rabo jezika v SMS-ju. Da gre tudi v tem primeru za svojevrsten kod, predvidevamo iz dejstva, da kakršnokoli vključevanje v SMS-komunikacijo zahteva t. i. SMS-pismenost, ki poleg poznavanja nekaterih značilnosti jezika SMS-jev vključuje vsaj še osnovno poznavanje delovanja mobilnega telefona.

Poskus ločevanja na uradno in neuradno SMS-komunikacijo s primeri ponazarjamo na podlagi že omenjenih skupin SMS-jev ter informacij, zbranih v sklopu diplomske naloge.

Tabelna predstavitev poskusne tipologije SMS-jev

\begin{tabular}{|c|c|}
\hline \multicolumn{2}{|c|}{ URADNA SMS-KOMUNIKACIJA } \\
\hline $\begin{aligned} & \text { Pošiljatelj } \\
= & \text { institucija }\end{aligned}$ & $\begin{array}{c}\text { Prejemnik } \\
=\text { uporabnik }\end{array}$ \\
\hline \multicolumn{2}{|c|}{ 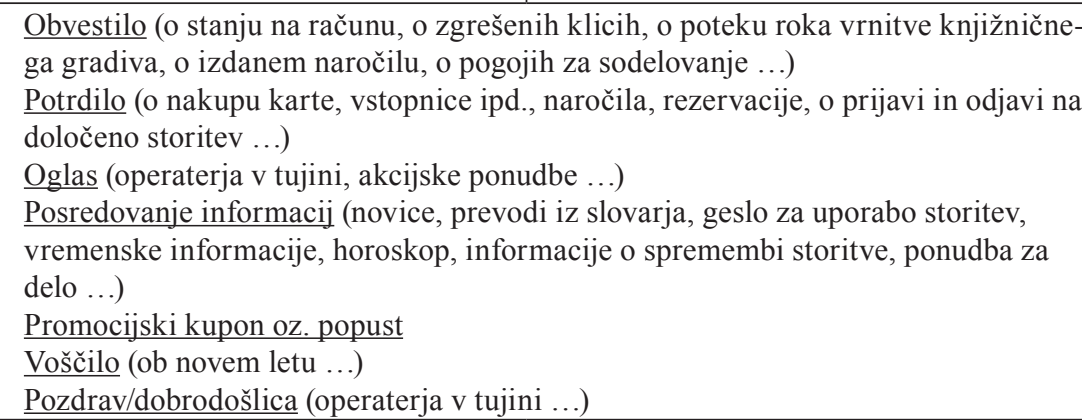 } \\
\hline $\begin{aligned} & \text { Pošiljatelj } \\
= & \text { uporabnik }\end{aligned}$ & $\begin{array}{l}\text { Prejemnik } \\
=\text { institucija }\end{array}$ \\
\hline $\begin{array}{ll}\text { - } & \text { Glasovanje } \\
\text { - } & \text { Nakup/plačilo (vozovni } \\
\text { - } & \text { Zahteva (za posredovan } \\
\text { - } & \text { Igre (kviz, križanka ...) } \\
\text { - } & \text { Donacija } \\
\end{array}$ & ...) \\
\hline
\end{tabular}

\begin{tabular}{|c|c|}
\hline \multicolumn{2}{|c|}{ NEURADNA SMS-KOMUNIKACIJA } \\
\hline $\begin{array}{c}\text { Pošiljatelj } \\
=\text { uporabnik }\end{array}$ & $\begin{array}{c}\text { Prejemnik } \\
=\text { uporabnik }\end{array}$ \\
\hline
\end{tabular}




\begin{tabular}{|c|c|c|c|c|c|}
\hline $\begin{array}{ll}\text { - } & \underline{\text { Poizvedova }} \\
\text { - } & \underline{\text { Oosredovan }} \\
\text { - } & \underline{\text { Potruba }} \\
\text { - } & \underline{\text { Voščilo }} \\
\text { - } & \underline{\text { Zahvala }} \\
\text { - } & \text {.. }\end{array}$ & informacij & & $\begin{array}{l}\text { Opravičilo } \\
\frac{\text { Pozdrav/do }}{\text { Želja }} \\
\frac{\text { Ukaz }}{\text { Prošnja }} \\
\underline{\text { Izražanje c }}\end{array}$ & ošlica & \\
\hline $\begin{aligned} & \text { Pošiljatelj } \\
= & \text { uporabnik }\end{aligned}$ & $\begin{array}{l}\text { Prejemnik } \\
=\underset{\text { uporab- }}{\text { nik }}\end{array}$ & $=$ & $\begin{aligned} & \text { Pošiljatelj } \\
= & \text { uporabnik }\end{aligned}$ & $\begin{aligned} & \text { Prejemnik } \\
= & \text { uporabnik }\end{aligned}$ & $\ldots$ \\
\hline Verižna sporočil & (̌ala, misel, & & oščilo, izražan & $\mathrm{v}$, druga spo & $\ldots)$ \\
\hline $\begin{aligned} & \text { Pošilj } \\
= & \text { upor }\end{aligned}$ & elj & & $\begin{aligned} & \text { Posrednik } \\
= & \text { institucija }\end{aligned}$ & $\begin{array}{r}\text { Prej } \\
=\text { brale } \\
\text { m }\end{array}$ & gega \\
\hline
\end{tabular}

V primerjavi z neuradno SMS-komunikacijo je v uradni poleg drugačnega jezika (zapis, besedišče ...) opazna še ena razlika, in sicer da enega od mobilnih telefonov navadno ${ }^{14}$ zamenja računalnik, tj. SMS-strežnik, ki je pogosto v lasti določene institucije, ki trži te komunikacijske storitve. Komunikacija med uporabnikom in institucijo lahko poteka izključno prek SMS-jev. SMS-strežnik namreč SMS-je lahko sprejema, obdeluje, hrani in nanje odgovarja. Uporabnik mobilnega telefona na številko strežnika pošlje SMS, ki vsebuje določeno ključno besedo in/ ali zaporedje ukazov, na podlagi katerih SMS-strežnik pošlje odgovor, zažene oz. ugasne izbrani program ipd.

- Uporabnik mobilnega telefona:

VREME CAS 5 1340 15

- SMS-strežnik:

(SMS 1) Narocilo je bilo sprejeto: VREME CAS 51340

(SMS 2) Danes se bo delno zjasnilo, pihal bo severovzhodnik, na Primorskem burja. Zjutraj bo od -8 do 4, cez dan od 0 do 9 st. $C$.

(SMS 3) Jutri bo povecini jasno, le na vzhodu in jugu bo bolj oblacno. Se bo vetrovno. Zjutraj bo od -11 do 0 , cez dan od -1 do 7 st. $C$.

(SMS 4) V nedeljo bo povecini jasno, v ponedeljek pa bo nekoliko vec oblacnosti. Se bo pihal severovzhodnik, na Primorskem burja.

»Uradni« SMS-ji so lahko tudi zgolj del komunikacije med uporabnikom mobilnega telefona in institucijo, ki v drugačnih oblikah nastopa prej ali potem oz. prej in potem.

${ }^{14}$ Potrebno je poudariti, da strogo ločevanje med uradno in neuradno SMS-komunikacijo z delitvijo glede na prenosnik (mobilni telefon oz. računalnik) ni mogoče, je pa pogosto.

${ }^{15} \mathrm{~S}$ to zahtevo uporabnik prijavi naročilo za prejemanje informacij v zvezi z vremenom, in sicer vsak petek ob 13. uri in 40 minut. 
- Uporabnik mobilnega telefona:

na študentskem servisu pusti svoje osebne podatke, vključujoč številko mobilnega telefona, in podatke o zainteresiranem področju dela.

- SMS-strežnik:

DELO Pouk slovenscine,pogoj-znanje spanscine,del.cas in placilo po dog. Klicite:031238387-ga.Gloria.LP,SS Borstnikov trg 012008813

- Uporabnik mobilnega telefona:

lahko pokliče kontaktno osebo.

Takšni SMS-ji, s stališča uporabnika so to prejeti SMS-ji, so v uradni komunikaciji zelo pogosti in navadno predstavljajo odgovor na predhodno poslani SMS uporabnika. Največkrat na ta način uporabnik mobilnega telefona prejme različne informacije oz. obvestila:

- najnovejše informacije,

09Dec17:21 Poslanke in poslanci so doslej podprli 5 od skupaj 140 vlozenih dopolnil k proracunu za 2006.(Neposredni prenos seje tudi na mobilnem Planetu.)

- vremenska napoved,

Danes se bo delno zjasnilo, pihal bo severovzhodnik, na Primorskem burja. Zjutraj bo od -8 do 4 , cez dan od 0 do 9 st. C.

- ponudba za delo,

GFK Gral-Iteo ponuja delo:anketiranje po podjetjih po celi Sloveniji.Obiski so vnaprej dogovorjeni.Placilo je 1.500 SIT/anketo.Inf.na 031333173-Sasa.

Lep dan

- obvestilo o zgrešenih klicih,

$+38631703207,21: 44$ 07/11

- obvestilo o stanju na računu mobilnega telefona,

Informativna poraba za 041264153 do vkljucno 13.11 .2005 je 4.003,74 SIT $\mathrm{z}$ DDV, brez popustov, z dospelimi racuni za storitve $\mathrm{v}$ tujini in nakupi prek Monete.

- obvestilo o izdanem naročilu.

Spostovani! Vase narocilo v enaA.com je pripravljeno za izdajo. Prosimo, da ga dvignete $\mathrm{v}$ petih delovnih dneh med 8.00 in 16.30 uro. Lep pozdrav, vas enaA tim!

V uradno SMS-komunikacijo bi lahko uvrstili tudi SMS-glasovanje. Glasovanje prek telefona je že dalj časa uveljavljeno, s pojavom mobilnih telefonov pa se je odprla nova možnost, in sicer glasovanje s SMS-jem. Svoj glas lahko oddamo v različnih anketah, lahko odločamo o zmagovalcu ipd. Anketa je pokazala, da med mladimi tovrstna storitev ni zelo razširjena, ker cenovno ni najbolj ugodna. $90 \%$ anketiranih učencev Gimnazije Poljane se namreč SMS-glasovanj ne udeležuje. Poslan SMS pa lahko pomeni tudi dobrodelno dejanje, gre za SMS-donacijo. Ta poteka tako, da v mobilni telefon vnesemo ključno besedo in SMS pošljemo na določeno 
številko. Cena je višja od cene SMS-ja po ceniku operaterja. S stališča uporabnika mobilnega telefona gre za primere poslanih SMS-jev.

Na meji med uradno in neuradno SMS-komunikacijo se nahajajo t. i. verižna pisma. Uporabnik mobilnega telefona prejme SMS, za katerega se pričakuje, da ga bo v enaki obliki odposlal naprej. Pošiljatelj takšnega SMS-ja navadno ni tudi njegov avtor. Avtor (ki sicer navadno ni pošiljatelj) je SMS namenil več naslovnikom, podobno kot se to dogaja v primerih avtomatičnega odgovora s SMS-strežnika, pogosto pa avtor SMS-ja na nek način tudi predstavlja določeno institucijo. Navajamo primera verižnega pisma, ${ }^{16}$ poslanega v obliki SMS-ja.

- Ta SMS prihaja iz RIMA. To noc pustite svecke prizgane na oknu ali balkonu kot priznanje in ljubezen PAPEZU. Poslji ta SMS vec osebam.NE GA PREKINITI!

- Poslji to snezinko *vsem svojim prijateljem in meni nazaj.Ce se ti vrnejo vsaj 3 v 24 urah,se ti bo zgodilo tisto,kar ze dolgo casa pricakujes PS SMS JE 4 SIT

\section{Kako napisati oz. »dešifrirati« SMS}

Primerjalno med »uradnimi« in »neuradnimi« SMS-ji bomo predstavili različne vrste krajšanja in komunikacijske obrazce na začetku in v zaključku SMS-ja. Jezik SMS-jev si bomo še nekoliko podrobneje ogledali v ožjem smislu besede, torej zanima nas jezik SMS-jev, kakršen se je pojavil predvsem med mladimi, ter njegove značilnosti (slengizmi, sloglish, emotikoni). Vprašali smo se tudi, kakšne so možnosti za standardizacijo takšnega novega jezikovnega koda.

\section{Krajšanje}

Način življenja, potreba po hitri komunikaciji ter specifično za SMS-komunikacijo - omejenost s prostorom; vse to so vzroki za vse večjo pojavnost krajšav predvsem v pisanih besedilih, ki pogosto prehaja tudi na govorjena. Oglejmo si nekoliko prirejeno klasifikacijo krajšav po Korošcu (1993, 15-27), z dodano posebno skupino, v kateri so krajšave, povezane $\mathrm{z}$ nastankom posebnega koda - jezika SMS-jev (in spletnega jezika).

KRATICA - lahko je inicialna ali neinicialna; v slovnici Gramática del español moderno $(1996,57)$ so kratice definirane kot besede, ki so nastale iz črk oz. zlogov drugih besed.

SIMBOL - ne nastane kot posledica krnitve, temveč je preprosto izbran za ločevalne značke.

${ }^{16}$ Dva primera za t. i. verižna sporočila navaja tudi Jarnovič (2006, 218-19): Izvoli zlato ribico $><>$ za sreco v zivljenju. Ti jo moras poslati naprej stirim prijateljem, drugace ti sledi smola. Imas en dan casa! :) in ******* TO JE 7 RITK BOZICKOVIH JELENOV. PRIPRAVLJAJO SE NA KAKANJE. HITRO JIH POSLJI NAPREJ, DA TI NE BODO ZASRALI CELO LETO 2006!. 
OKRNJENKA - v tej skupini krajšav ločimo odzadnjo in odsprednjo krnitev.

OKRAJŠAVA IN OKRAJŠANKA - okrajšano zapisana beseda ali besedna zveza, zaznamuje jih pika. Okrajšanka je priložnostna.

POSEBNA SKUPINA - tipična za jezik SMS-jev, kjer dele besede nadomešča matematični znak oz. številka, ki je izgovorjena enaka ali vsaj podobna delu besede, katerega zamenjuje (npr. ju3); drugi sklop so t. i. e-tvorjenke (Logar 2003b, 122), kjer morfem e- največkrat nadomešča pridevnik elektronski. V to skupino uvršamo tudi spletne domene.

Primeri krajšav iz neuradne in uradne SMS-komunikacije

\begin{tabular}{|c|c|c|}
\hline KRAJŠAVE & „»neuradni« SMS-ji & »uradni« SMS-ji \\
\hline KRATICA & $\begin{array}{l}\text { rtm - rada te mam } \\
\text { rd - rojstni dan } \\
\text { rtmf - rada te mam ful } \\
\text { rtm olpn - rada te mam od lune } \\
\text { pa nazaj } \\
\text { na pkk-ju - profesionalno, krea- } \\
\text { tivno, kvalitetno } \\
\text { s SMS-jem (iz angl.) } \\
\text { ok (iz angl.) } \\
\text { gsm (iz angl.) } \\
\text { sms (iz angl.) } \\
\text { msn (iz angl.) - Messenger } \\
\text { lol (iz angl.) - laughing out loud }\end{array}$ & \begin{tabular}{|l|}
$L P-$ lep pozdrav \\
$S S-$ Sttudentski servis \\
GFK (iz angl.) - Growth from \\
Knowledge \\
$D D V$ - davek na dodano vred- \\
nost \\
$P S$ (iz lat.) \\
$S M S$ (iz angl.) \\
$M M S$ (iz angl.) \\
$G P R S$ (iz angl.)
\end{tabular} \\
\hline SIMBOL & $h$ (iz angl.) - hour & $C-$ Celzij \\
\hline $\begin{array}{l}\text { OKRNJENKA } \\
\text { a) odzadnja krnitev }\end{array}$ & $\begin{array}{l}\text { babi - babica } \\
\text { za gefo - za geografijo } \\
\text { kemo - kemijo } \\
\text { anglo - angleščino } \\
\text { mato - matematiko } \\
\text { na comp (iz angl.) - na com- } \\
\text { puter } \\
\text { med kontro - med kontrolno } \\
\text { nalogo } \\
\text { za kemo - za kemijo } \\
\text { pr mati - pri matematiki } \\
\end{array}$ & Info-informacije \\
\hline $\begin{array}{l}\text { b) odsprednja krnitev } \\
\text { OKRAJŚAVA, } \\
\text { OKRAJŠANKA }\end{array}$ & $\mid$\begin{tabular}{|l} 
lenki-Alenki \\
$v p$ - vprašati
\end{tabular} & $\begin{array}{l}\text { ga. - gospa } \\
\text { d. } d . \text { - delniška družba } \\
\text { st. - stopinj } \\
\text { del.cas - delovni čas } \\
\text { po dog. - po dogovoru } \\
\text { Inf.na - informacije na }\end{array}$ \\
\hline POSEBNA SKUPINA & $\begin{array}{l}u 3-\text { jutri } \\
=z i k-\text { jezik } \\
j u 3-\text { jutri }\end{array}$ & $\begin{array}{l}\text { e-nostavna - elektronska enos- } \\
\text { tavna } \\
\text { e-Studentskega - elektronskega } \\
\text { Študentskega } \\
\text {.net }\end{array}$ \\
\hline
\end{tabular}


Primerjava med »neuradnimi« in »uradnimi« SMS-ji pokaže, da je največja razlika v okrnjenkah, ki jih v »uradnih« SMS-jih skoraj ni, dijaki pa jih pogosto uporabljajo. Okrajšave prevladujejo v »uradnih« SMS-jih. Kratic je veliko v obeh skupinah SMS-jev, prevladujejo inicialne, torej sestavljene iz prvih črk besed.

V skupini okrnjenk (odzadnja krnitev) med SMS-ji iz anket izstopa velika skupina poimenovanja šolske stvarnosti. Navajamo primere:

- Ej men se tok nč ne da ... prou useen mi je za to gefo.

- Kemo s sabo - deal!

- A znaš anglo?

- mato sm 3 dobla!

- Pa bi napisala nazaj da bi ti pomagu med kontro.

- ej dej mi jutr prnes une liste za kemo!!

- Mi bos povedu ka ste jemal pr mati dons in mi razlozu uno nalogo s kroznco.

\section{Komunikacijski obrazci na začetku in v zaključku SMS-ja}

Poudariti je potrebno, da je pojavnost klasičnih pozdravov tako na začetku kot tudi na koncu obeh skupin SMS-jev izredno nizka. Pogost komunikacijski obrazec na začetku »neuradnih« SMS-jev je ej (7 primerov in varianten ei), ki ima predvsem apelativno funkcijo (podobno kot ime naslovnika), sicer zasledimo še Čaw/Caw/ $\mathrm{Cao}, \mathrm{Hei} / \mathrm{Hey} / \mathrm{Hej}$, Živjo, Hi. Poleg dejstva, da smo pri pisanju SMS-jev omejeni s prostorom, lahko to nizko pojavnost klasičnih pozdravov razlagamo tudi s tem, da posamezen SMS predstavlja le del komunikacije. Tako se v primeru »uradnih «SMSjev v zaključku velikokrat pojavljajo druge informacije, npr. kontaktna telefonska številka (a), naziv podjetja (b) in v kombinaciji lahko še kontaktna oseba (c):

- (a) kontaktna telefonska številka

[...] Za turisticne informacije poklicite 1555 . Klic se zaracuna.

[...] 031841841

[...] Info: 015134444

[...] Naroci napotnico 041314151

[...] Narocilo napotnice: 041314151

- (b) naziv podjetja

[...] Prijetno uporabo vam zeli druzba Mobitel!

- (c) kontaktna telefonska številka ter naziv podjetja in/ali kontaktna oseba

[...] Klicite:031238387-ga.Gloria.LP,SS Borstnikov trg 012008813

[...] Za dodatne informacije poklicite 041700700. Mobitel, d. d.

[...] Inf.na 031333173-Sasa.Lep dan.

V skupini »neuradnih« SMS-jev na mestu pozdravov zasledimo vzorce kombinacij imena oziroma vzdevka pošiljatelja s pozdravom:

- (a) ime/vzdevek + pozdrav 
[...] Kemo s sabo - deal! neSa *ta ta*

- (b) pozdrav + ime/vzdevek

[...] Te zvrcnem k utegnm ... Ajd ese.

- (c) ime/vzdevek

[...] vale? nesic + odpis plosm.

V zaključku SMS-ja so predvsem v skupini »neuradnih «SMS-jev pogosti tudi drugi izrazi. Zasledimo »poljub « $m w a$, krajšavi $r t m, r t m f,{ }^{17}$ kar lahko razvežemo v rad/a te mam (ful), ki prav tako v SMS-jih zamenjujejo običajnejše pozdrave. V zaključku so pogosti tudi emotikoni, vendar nekatere lažje, druge težje prepoznamo $v$ funkciji pozdrava.

\section{Slengizmi}

»Sleng je neformalna varianta občevalnega jezika, ki jo označuje poseben slovar, sestoječ bodisi iz novih izrazov ali pa iz starih z novim ali drugače zaobrnjenim pomenom « (Gjurin 1974, 65). Afektacija in ekspresivnost sta dve tipični značilnosti slenga in zdi se, da je prioriteta presenetljiv način upovedovanja (Gjurin 1974, 65). Sleng je prisoten tudi v jeziku SMS-jev in je zato predmet obravnave. Gjurin (1974, 66) loči med (a) slengovsko besedo, ki v drugih zvrsteh ne nastopa, in (b) slengizmom, ki ima $v$ drugih zvrsteh drugačen pomen. Obe skupini slengovske besede lahko najdemo tudi v SMS-jih.

(a) Prvi primer je slengovski izraz, glagol zvrcniti, ki v tem kontekstu pomeni pustiti neodgovorjen klic in ga $\mathrm{v}$ drugih zvrsteh jezika ne zasledimo.

Pol k boš lah mi zvren pa te back pokličm.

(b) Fonetičen zapis glagola zalivati ne nastopa v prvotnem pomenu, temveč je $\mathrm{v}$ povezavi s pitjem (alkoholne) pijače. $\mathrm{V}$ tem primeru torej prepoznamo drugo skupino slengovskih izrazov.

Ob 15 do $3 \mathrm{~h}$ sam bom zaliwala zadno uro!

Posebna oblika slenga je mladostniški sleng. Jezik anketirane skupine bi sodil $\mathrm{v}$ podvrsto srednješolskega slenga. Na splošno pa tovrstni sleng zaznamuje raba vulgarizmov, obscenega besedja in barbarizmov ter vrednostna ekstremizacija (Gjurin 1974, 72). V zbranih SMS-jih naštete značilnosti niso pogoste. ${ }^{18}$

\section{Sloglish}

Poglavitno mesto pri prevzemanju iz tujih jezikov v slovenščino ima angleščina. Angleščina kot lingua franca danes prodira v večino jezikov, zato so izrazi za poimenovanje mešanja jezika $\mathrm{z}$ angleščino, kot je sloglish, uveljavljeni tudi za druge

${ }^{17}$ Podobna je situacija v španščini: muack, muak, 1 besazo, besines itd. Cntst, cht, con so v španskih SMS-jih krajšave za contesta, s katerimi apelirajo na naslovnika, naj odgovori.

${ }^{18}$ Nekaj vulgarizmov v SMS-jih opazimo pri Orel (2003, 419): pi*** ti materna, kdo si posilja msge?! in Spizdi nekam. 
jezike. Zdi se, da so mlajši še bolj dovzetni za tovrstno prevzemanje. V anketah se pojavljajo primeri vpliva tujih jezikov, ki bi jih lahko razdelili v dve večji skupini in sicer glede na količino prevzemanja.

PREVZETOST: V anketah dijakov se pojavljajo izrazi, ki so v slovenščino prevzeti iz angleščine. Poglejmo si primere iz SMS-jev, ki so jih dijaki prepisali iz svojih mobilnih telefonov: kul, plis, ful, pliz, frendow, sorcy, sori, sory, dilci, plz, crackat.

CITATNOST: Tudi citatnih izrazov je $\mathrm{v}$ anketah dijakov precej, v primerih SMS-jev anketiranci navajajo: baby, joke, and, $d$ sweetest thing, the sweetest thing, comp, sorry, ok, HAPPY BIRTHDAY!, a lot of love, back, $u$ know me, homie, from my lips, okay, peace, fakin, crack.

Poleg zelo vplivne angleščine $v$ jeziku SMS-jev zasledimo tudi prevzemanje iz drugih jezikov. Pogosta je italijanščina, in sicer predvsem v pozdravih (cao in čaw/ caw). V jeziku SMS-jev zasledimo še španščino ${ }^{19}$ (metek sdaj sm spala, pozabla te poklicat. mam pa idejo ... manana a las siete y media en elipsa para contarte todo que ha pasado. vale? nesic + odpis plosm.) ter precej močen vpliv srbščine/hrva-

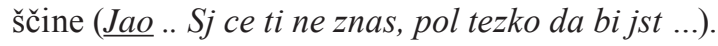

\section{Emotikoni}

Za zgodovinski začetek emotikona bi lahko šteli nastanek nasmejanega rumenega obrazka, ki ga imenujemo tudi »smiley« (angl.), smeško, smejko ali znamenka. To se je zgodilo ob združitvi dveh zavarovalniških družb leta 1963. Grafika Harveyja $R$. Balla so novi direktorji najeli z namenom dviga morale in vsesplošnega vzdušja. V SMS-jih se je emotikon uveljavil preko spleta, kjer se je prvič pojavil leta 1982 na pobudo Scotta Fahlmana, raziskovalca na univerzi Carnegie v Pittsburgu. Poslal je sporočilo z naslednjo vsebino: (Glej: Prvi emotikon na spletu na naslednji strani $)^{20}$

Prvotno je bil torej emotikon mišljen za označevanje šal, danes pa je raba emotikona mnogo širša. $Z$ emotikonom lahko izražamo »svoje čustveno stanje (ali več), (čustveni) odnos do prejemnika ali predmeta obravnave, besedilo s tem ekspresivno obarvamo.« (Mesarić 2005: 70).

Ja burek se ful dobr slišs! d sweetest thing ... ooo ... moram jet k mi je babi prek duhovov puwedala d si morm jet zobe umit :-) lol

»Včasih imajo emotikoni zgolj estetsko vlogo: besedilo je opremljeno z emo-

${ }^{19}$ Najverjetnejši vzrok vpliva španščine, ki sicer v slovenščini nima vidne vloge, je najbrž to, da je eden izmed izbirnih predmetov anketiranega razreda tudi španščina.

${ }^{20} \mathrm{~V}$ prostem prevodu: »Naslednje zaporedje znakov predlagam za označevanje šal: / :-) / Za branje glavo obrni na stran. Pravzaprav pa je, glede na sedanje trende, najbrž bolj gospodarno zaznamovati stvari, ki NISO šale. Za to uporabi / :-(« (Vir: http://infade. blogspot.com/2005/09/felicidades.html, 5. 12. 2005). 
tikoni z namenom, da deluje privlačno, zabavno, razgibano, s čimer se razodevajo lastnostne poteze sporočevalca (Mesarić 2005, 70). Podobno vlogo imajo lahko tudi druga pisna znamenja (npr. * in $\sim$ ).

ooo bravo ewa!!! tanja je bedna :-) sam morš pa rečt da ga bar rula! in kako si ti lubika moja? pridna bot *mwa*

»Emotikoni lahko stojijo kjerkoli v besedilu, običajno so postavljeni na konec stavka ali povedi za končnim ločilom ali celo vplivajo na njegov izpust« (Mesarić 2005, 70; povz. po Crystal 2001, 36).

ooo bravo ewa!!! tanja je bedna :-) sam morš pa rečt da ga bar rula! in kako si ti lubika moja? pridna bot *mwa*

Prvi emotikon na spletu

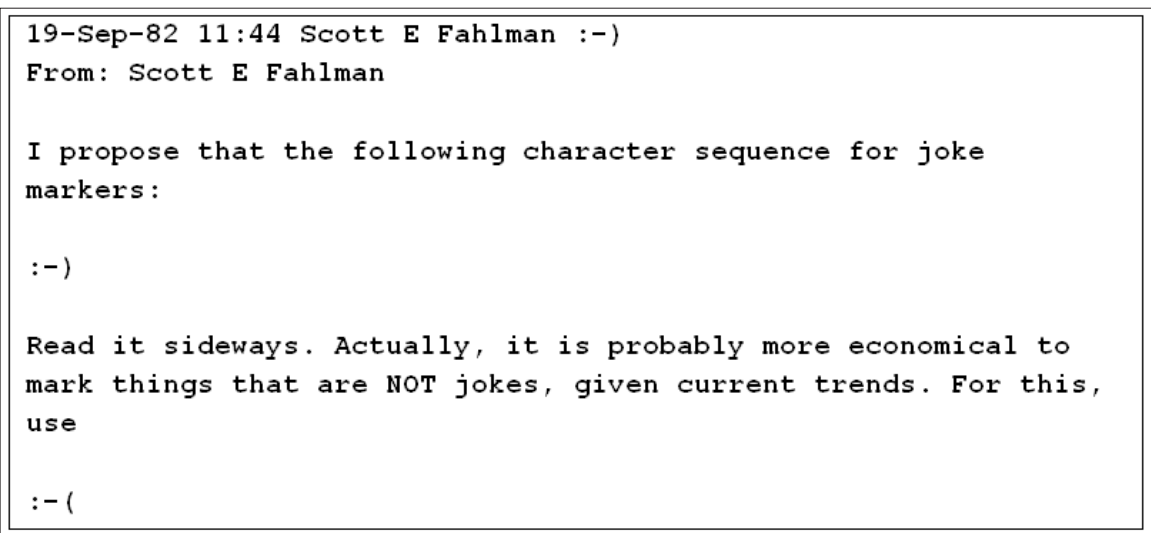

\section{Smiselnost standardizacije}

Na spletu in tudi v tiskani obliki najdemo kar nekaj literature o tem, kako pisati SMS-je, vendar se izkaže, da se večina teh pravil v praksi ne potrdi. Še najbolj uporabna za pisanje SMS-jev se zdi na tem mestu maksima, ki se glasi: »Uporabne so vse kombinacije, ki so dovolj jasne, da jih razume normalno pismen človek. $\|^{21}$ Ameriški študentje, ki naj bi bili začetniki kratkopisa, so se držali maksime »piši, kot misliš, da se napiše«, vendar se vsaj za razmere v slovenskem jeziku SMS-jev zdi primernejša maksima »piši, kot govoriš«. Pogost napotek za boljši izkoristek prostora pri pisanju SMS-jev je krajšanje s pomočjo zamenjave dela besede oz. cele besede $\mathrm{z}$ matematičnim znakom, npr. $=z i k(j e z i k)$ ali pa nadomeščanje dela besede oz. cele besede z rabo številk, npr. 5ek (petek). Pri anketiranih je bil tovrsten način zapisa redek. Za primer vzemimo besedo jutri, ki so jo morali dijaki v eni od nalog v anketi »prevesti« v jezik SMS-jev. Za zapis $j u 3$ se je odločilo 9 dijakov od skupno

${ }^{21}$ Povzeto po Mobitelovi brošuri Slovenski kratkopis. 
29 , enkrat je uporabljen varianten $u 3$, večina pa je uporabila fonetičen zapis jutr. Podobno je bilo pri besedici petek, kjer so le trije dijaki uporabili zapis s številko $5 k$ oz. $5 e k .{ }^{22} \mathrm{Za}$ dodatno ponazoritev dodajmo še primer variant zapisa besede dolgčas iz ankete dijakov z Gimnazije Poljane.

\section{Variante zapisa besede »dolgčas« v anketi}

\begin{tabular}{|l|l|l|l|}
\hline dolgčas & fantje & dekleta & skupaj \\
\hline dougcajt & 3 & 7 & 10 \\
\hline dolgcajt & 0 & 5 & 5 \\
\hline dougčas & 0 & 4 & 4 \\
\hline dolgčas & 1 & 1 & 2 \\
\hline tuga & 1 & 1 & 2 \\
\hline dowgcajt & 0 & 1 & 1 \\
\hline douhcajt & 0 & 1 & 1 \\
\hline boring & 0 & 1 & 1 \\
\hline bedno & 0 & 1 & 1 \\
\hline dougčs & 0 & 1 & 1 \\
\hline bedn & 0 & 1 & 1 \\
\hline & 5 & 24 & 29 \\
\hline
\end{tabular}

Jezik SMS-jev torej ima svoje značilnosti, vendar pa se zdi, da vse te značilnosti niso specifične zgolj za jezik SMS-jev in da jih poznamo že od prej. Sleng se je že mnogo prej pojavil med mladimi, slengovske besede opazimo v neuradni SMS-komunikaciji, teh izrazov pa v uradni SMS-komunikaciji ni zaslediti. Jeziki so bili vedno v stiku z drugimi jeziki, vplivali drug na drugega in tako je še danes. Krajšanje besed poznamo iz zapiskov, stenografije. Pomanjkanje prostora je vplivalo na pisanje »plonk« listkov. Emotikone bi lahko primerjali z načinom izražanja čustev v pismih mladostnikov ( $x$ npr. je že davno pred SMS-ji nadomeščal poljub). Za jezik SMS-jev je značilno tudi opuščanje ločil, ki ga poznamo iz telegramov. Tudi problem, ki se ga v prispevku nismo dotaknili, opuščanje strešic na šumevcih, ${ }^{23}$ je že v preteklosti predstavljal težavo, in sicer v dobi, ko tehnologija tiska še ni bila tako napredna. Strešice je bilo potrebno pisati na roke. Vse te značilnosti jezika SMS-jev na nek način torej poznamo že od prej, novost pa vsekakor predstavlja

${ }^{22} \mathrm{Na}$ tem mestu se pojavi vprašanje smiselnosti standardizacije jezika SMS-jev, kot so to poskusili narediti v katalonščini. Profesorici z Balearskih otokov, Caterina Canyelles in Margalida Cunill, sta sestavili nekakšen pravopis za pisanje SMS-jev. Primeri: za zapis $c a$ pišemo $k$, que zamenjamo s $q$, qui s $q i, c u$ s $q$ itd. Glede na sorodnost španskega in katalonskega jezika predpostavimo, da je način pisanja SMS-jev v teh dveh jezikih podoben. Vzemimo za primer špansko besedo (iz ankete) quedamos, ki vsebuje niz que, za katerega Canyelles in Cunill predlagata zapis $q$. To besedo so španski dijaki morali zapisati na način, kot bi jo zapisali v SMS. Variante zapisa so: kdamos, qdms, qdamos, quedamos, qedms, kdms, qdams, kedamos, kedms, kedam, $Q D$, kdmos. Niz que je torej zapisan na pet različnih načinov, s $k, q$, que, qe, $k e$ in $Q$. Zdi se, da takšna detajlna standardizacija jezika SMS-jev ni ne uporabna ne smiselna.

${ }^{23}$ Pri tem problemu gre predvsem za tehnološko pomanjkljivost. 
hkratna pojavitev vseh teh pojavov v SMS-jih (in na spletu), njihova splošno razširjena uporaba in večja dostopnost teh besedil. Majhna tipkovnica, ki dela pisanje SMS-jev zamudno, in omejitev na 160 znakov sta pomanjkljivosti v komunikaciji in jezik se je moral prilagoditi na kanal. Razumljiva je skrb številnih jezikoslovcev in učiteljev, da mladi ne bodo znali več pravilno pisati, po drugi strani pa je običajno, da pride do nastanka novega koda v situacijah, kjer so pogoji za sporazumevanje specifični (gluhi - kretalni jezik, slepi - braillova pisava, stenografija - krajšanje, SMS - jezik SMS-jev ...), vendar to še ne vpliva nujno na pismenost in spremembo standardnega jezika (Grijelmo 2004, 233-48).

\section{Zaključek}

SMS-ji so postali del našega vsakdana, nekaj, kar se je močno usidralo, in izgleda, da jih bodo MMS-ji, čeprav poleg možnosti pošiljanja melodije in slike omogočajo tudi posredovanje besedila, težko nasledili. Ta pojav pa od nas zahteva novo, drugačno opismenjevanje, ki temelji na določenem poznavanju novih tehnologij, predvsem mobilnih. Vse to se stopnjuje v poznavanju novega načina komuniciranja, ki se je pojavil večinoma med mladimi. Nedvomno je imel pomemben vpliv na ta novodobni pojav tudi hiter način sodobnega življenja, kar je povzročilo, da na primer v komunikaciji izginjajo običajni pozdravi. Standardizacija jezika SMSjev se $\mathrm{v}$ tem trenutku še ne zdi smiselna - predvsem zaradi prevelike variantnosti v zapisu, kar se je pokazalo na primeru ankete dijakov Gimnazije Poljane. Lahko pa bi bil uporaben nabor različnih zapisov besed v jeziku SMS-jev, kot je bil predstavljen na primeru besede »dolgčas«. Takšen nabor bi sestavljali mladi sami, na primer na spletni strani, ${ }^{24}$ ki bi lahko služila kot pomoč za »dešifriranje«, hkrati pa tudi kot SMS-korpus, s pomočjo katerega bi se s časom skristaliziralo, katere izraze, kakšne okrajšave ipd. se dejansko uporablja v jeziku SMS-jev. Treba je tudi poudariti, da se pravila za pisanje SMS-jev, kakršna zasledimo na spletu, pa tudi v tiskani obliki, $v$ anketi niso povsem potrdila, saj se bolj kot recimo nadomeščanje dela besede z matematičnim znakom oz. številko uporablja fonetični zapis. Dejstvo je, da jezik SMS-jev, predvsem kakršnega poznamo med mladimi, prinaša določene novosti, vendar ne smemo pozabiti, da obstaja tudi uradna SMS-komunikacija, kjer pošiljatelji teh SMS-jev pogosto upoštevajo pravopisna načela. Prihodnost jezika SMS-jev in SMS-komunikacije pa je odvisna tudi od nadaljnjega razvoja mobilnih tehnologij, saj pogosto prav tehnološke omejitve vplivajo na jezik SMS-jev in SMS-komunikacijo.

\section{Literatura}

Crystal, David, 2001, Language and the Internet, Cambridge, Cambridge University Press.

${ }^{24}$ Takšna spletna stran obstaja za jezik SMS-jev v španščini: www.diccionariosms.com, ki je rezultat raziskovalnega projekta in s katerim želijo »pomagati staršem, profesorjem in jezikoslovcem bolje spoznati to realnost $\ll$. 
Gjurin, Velemir, 1974, Interesne govorice sleng, žargon, argo, Slavistična revija, 22, 1. Maribor, Založba Obzorja, 65-81.

Gramática del español moderno, 1996, Madrid, Santillana.

Grijelmo, Álex, 2004, El genio del idioma, Madrid, Taurus.

Jarnovič, Urška, 2006, Sms-ov glas seže v deveto vas, Novak Popov, Irena (ur.), 42.

SSJLK, Mesto in meščani v slovenskem jeziku, literaturi in kulturi, Ljubljana, Filozofska fakulteta, Oddelek za slovenistiko, Center za slovenščino kot drugi/ tuji jezik, 215-19.

Korošec, Tomo, 1993, O krajšavah, Hladnik, Miran (ur.), XXIX. Seminar slovenskega jezika, literature in kulture, Ljubljana, Filozofska fakulteta, 15-27.

Logar, Nataša, 2003a, Kratice in tvorjenke iz njih - aktualna poimenovalna možnost. Stanisław Gajda, Vidovič Muha, Ada (ur.), Wspótczesna polska i stoweńska sytuacja językova, Sodobni jezikovni položaj na Poljskem in v Sloveniji, Opole, Instytut Filologii Polskej, Filozofska fakulteta, 131-149.

Logar, Nataša, 2003b, Nove tehnologije in nekateri nesistemski besedotvorni postopki. Kržišnik, Erika (ur.), Obdobja 22. Metode in zvrsti, Ljubljana, Filozofska fakulteta, 121-131.

Mesarić, Alen, 2005, SMS-besedilnost, Neobjavljeno diplomsko delo, Maribor, Univerza v Mariboru, Pedagoška fakulteta, Oddelek za slovanske jezike in književnosti.

Michelizza, Mija, 2006, Pragmatična primerjava jezika SMS-jev v slovenščini in španščini, Neobjavljeno diplomsko delo, Ljubljana, Univerza v Ljubljani, Filozofska fakulteta, Oddelek za slovenistiko.

Orel, Irena, 2003, Sporazumevanje nekoč in danes - od vzorcev pogovorov do mladostniških SMS-ov. Kržišnik, Erika (ur.), Aktualizacija jezikovnozvrstne teorije na Slovenskem - Členitev jezikovne resničnosti, Mednarodni simpozij Obdobja - metode in zvrsti, Ljubljana, Filozofska fakulteta, Oddelek za slovenistiko, Center za slovenščino kot drugi/tuji jezik, 407-22.

»Passa-ho« en catalán, ABC Nacional, 7. januar 2005, 30.

Picture messaging, Lack of text appeal, The economist, 5. avgust 2006, 56.

Strehovec, Janez, 2004, Pismenost za svetovni splet: kako brati digitalna novomedijska besedila, Jezik in slovstvo 49/1, 83-96.

\section{SMS Language and SMS Communication}

\section{Summary}

This article discusses SMS as a means of communication that is universally widespread today among both young and somewhat older cell phone users. It examines the history of SMS and assesses the possibility that MMS may soon supplant it, although MMS does not seem as popular as SMS. Based on SMS communication, which is an important part of everyday life, literacy no longer merely refers to the ability to read and write. Short text messages are replacing telephone calls and are used to send congratulations and invitations to parties, to obtain information, 
$-\quad$ to vote, to make donations, and for other purposes. Short text messages are therefore replacing spoken and written texts and may be part of casual or formal SMS communication. Two groups of SMS examples are analyzed: casual messages contributed by students from the Poljane Secondary School in Ljubljana, and formal messages collected by the author (from the service provider, advertisements, etc.). The World Wide Web, slang, the general penetration of English, and a limitation to 160 characters have had a decisive influence on the emergence of a new code: SMS language, the most innovative feature of which is that all of these characteristics occurred simultaneously. This is a manner of writing that has primarily arisen in casual SMS communication, although some of its features are also seen in formal communication. The effect of various attempts to standardize SMS language, and the degree to which this is applied in practice, is also examined.

Mija Michelizza

Inštitut za slovenski jezik Frana Ramovša ZRC SAZU

Novi trg 2, 1000 Ljubljana 